\title{
Spatial mobility of knowledge transfer and absorptive capacity: analysis and measurement of the impact within the geoeconomic space
}

\author{
Mario Coccia
}

Published online: 28 April 2007

(C) Springer Science+Business Media, LLC 2007

\begin{abstract}
This paper analyses the spatial mobility of knowledge and technology transfer and measures the economic impact on the geo-economic space. The data of laboratories operating in different research and technological fields are used. The results show that, when the distance from the source of knowledge (research institute) to users increases, the impact of knowledge and technology transfer decreases with damped pulsations. The magnitude of knowledge and technology transfer shows a high intensity within the industrial district because small businesses are able to acquire externally scientific knowledge, without conducting in-house research, but by interactions with public scientific bodies and adopting both collective rules that act as collective knowledge devices, making collective learning possible, and skilled labor.
\end{abstract}

Keywords Absorptive capacity · Economic impact - Knowledge spillover . Learning process - Patterns of technological innovation · Research institutes · Technology transfer

JEL Classifications $\mathrm{C} 00 \cdot \mathrm{L} 30 \cdot \mathrm{O} 14 \cdot \mathrm{O} 30 \cdot \mathrm{O} 32 ; \mathrm{R} 10$

\section{Introduction}

Innovation and technical change play more and more a fundamental role in the knowledge era for competitiveness of firms and economic growth of countries (Aghion $\&$ Howitt, 1998). The modern literature on economics of innovation and technical

M. Coccia $(\varangle)$

National Research Council (Italy), CERIS-CNR, Institute for Economic Research on Firm and Growth, Collegio Carlo Alberto-via Real Collegio, n. 30, 10024 Moncalieri, Torino, Italy e-mail: m.coccia@ceris.cnr.it

M. Coccia

Max Planck Institute of Economics, Kahlaische Straße, 10, 07745 Jena, Germany 
change has developed new approaches that include spatial context in patterns of innovation. In fact, geographic space has become key factor in explaining the origin and diffusion of innovation and several scholars are engaged to understand the role of technology and knowledge within this spatial black box. Krugman (1991) argues that the geography of economic activities is based on spatial concentrations and according to Feldman (1994) this is true both for production and innovative activities. The models of knowledge production have been found to hold better for spatial units of observations than for enterprises in isolation of spatial context. In particular, the purpose of new economic literature is to understand the spatial dimension of mechanisms that underlie the propensity of innovative activity to cluster spatially, the mobility of knowledge and technology transfer, the absorptive capacity of adopters on the geoeconomic space, and so on. Technology transfer and knowledge spillover are prominently in addressing these issues. In fact, knowledge created in research laboratories is an important source of technology (Acs, Audretsch, \& Feldman, 1994; Premus, 2002; Coccia, 2006) and knowledge spillover (Jaffe, 1989; Griliches, 1992; Zucker, Darby, \& Armstrong, 1998). Technology transfer can be viewed as an active process by which technology is carried across the border of two entities such as countries (international technology transfer), firms, or even individuals, depending on the viewpoint of the observer (Autio \& Laamanen, 1995). New research on technology transfer has grown enormously and Bozeman (2000) synthesizes this voluminous literature using a contingent effectiveness model of technology transfer that considers five dimensions: (1) transfer agent; (2) transfer medium; (3) transfer object; (4) transfer recipient; (5) demand environment. In particular, scholars focus the economic analysis of knowledge and technology production, transfer and diffusion on two research fields. The first is the theoretical basis for technology to transfer and knowledge to spill over with the aim to penetrate the black box of geographic space. The second challenge involves the measurement. Moreover, the literature does not address the path and impact that technology transfer and knowledge spillover take on geo-economic space. Lucas (1988, 1993), Grossman and Helpman (1991) shed little light on actual mechanism by which technology and knowledge are transmitted across individuals, whereas Krugman (1991) argues that empirical measurement of knowledge is a difficult undertaking due to invisible or tacit flows (Polanyi, 1966). In fact, recurrent questions are: Which is the mechanism of transmission of technology and knowledge? How could impact of technology and knowledge be measured? To answer these important economic questions, the paper presents an alternative metrics in order to analyze the spatial mobility of technology and knowledge (Brown, 1968) and measure their economic impact on domestic geo-economic space.

This new approach can help to examine the degree to which technology and knowledge spillover are geographically localized and spatially bounded. In fact, policy makers and managers need to know how strategically invest in the development of absorptive capacity of technology transfer and knowledge spillover to enhance the competitive advantages of firms and nations (Porter, 1990). Thus while the endogenous growth theory (Romer, 1990) emphasizes the importance of investment in research and human capital, it may be useful to map the process by which technology and knowledge is created, externalized and commercialized, since this is the key to provide the microeconomic linkages to endogenous macroeconomic growth. Before to describe this metrics and the application on some case study, let me introduce the studies that analyze the black box of geographic space by focusing the role of technology and knowledge. 


\section{Theory}

First of all it is necessary to clarify some concepts since technology transfer, knowledge transfer and knowledge spillovers are called in different manner but may represent similar phenomena. Knowledge, in evolutionary perspective (Nelson \& Winter, 1982), is an important element within technology set. Technology as knowledge ${ }^{1}$ allows firms to accumulate know-how which is the precondition for generating innovations and raise the productivity and competitiveness (Wersching, 2005). Technologies as well as knowledge are localized (Antonelli, 1995) since depend on learning process (learning by doing Arrow, 1962; by using-Rosenberg, 1982; and by interacting-Lundvall, 1992; Malerba, 1992) and path dependence (David, 1993). It is not sufficient to create technology into research labs for increasing economic growth, but it is also necessary to transfer it into geoeconomic space. Figure 1 shows the main subjects of technology-knowledge transfer and diffusion process (Coccia, 2005).

The transfer from scientific system to productive-commercial system is not automatic (Rogers, Takegami, \& Yin, 2001; Kremic, 2003) and it is necessary that research laboratories have interactions and interrelatedness with firms and public institutions (Roessner \& Bean, 1994) by a triple-helix model (Etzkowitz \& Leydesdorff, 2000). Knowledge and technology transfer between organizations, groups or areas that differ in terms of customs, age, social status, financial position, receptivity and production activities are less probable. Technology and knowledge are important inputs within economic space such that firms prefer a nearby location to research institutes (sources of knowldge), even if the cost of other factors is higher. Asheim and Gertler (2005) claim “... one simply cannot understand innovation properly if one not appreciate the central role of spatial proximity and concentration in this process'. The empirical literature suggests that geographical proximity leads to a faster technology and knowledge transfer (Keilbach, 2000; Meagher \& Roger, 2004). The spatial analysis of knowledge transfer received a first important contribution with Hägerstrand (1967), who stated that when the physical distance from the source of knowledge increases, the users' adoption of information decreases: the so-called neighborhood effect is due to lower probability of contact among subjects when the distance increases. Feldman (1994), Audretsch and Feldman (1996) have highlighted the importance of physical distance in innovation and technology transfer process too. Saxenian (1995) whereas shows that physical proximity and greater interdependence among individuals lead to higher technology transfer than subjects more isolated and less interdependent. In fact, the economic space (Perroux, 1967) creates economic and technological interactions among subjects, such as productive units (firms), public administrative bodies and sources of knowledge (universities, research institutes) that generate flows of information and goods. Geographical and technological proximity (Bellet, Kirat, \& Largeron, 1998; Boschma, 2005) of economic agents are seen as main factors to knowledge transfer, since both kinds of proximity have an impact on learning capabilities of firms (Lundvall \& Johnson, 1994; Sutton, 1998). The proximity of subjects can be measured by interactions of technological, spatial and organizational nature. The French school of proximity (Gilly \& Torre, 2000; Pecqueur \& Zimmermann, 2004; Torre \& Mollard, 2004; Singh, 2005; Torre \& Rellet, 2005) introduces the concept of density, which includes the number of interactions, but also their reproduction, duration and degree of transitivity. Rappa and Debackere (1992), Autio and Laamanen (1995) suggest that the evaluation of technology

\footnotetext{
1 Knowledge is information linked to a purpose through a process of individual and organizational interpretation (Daft \& Lengel, 1986).
} 


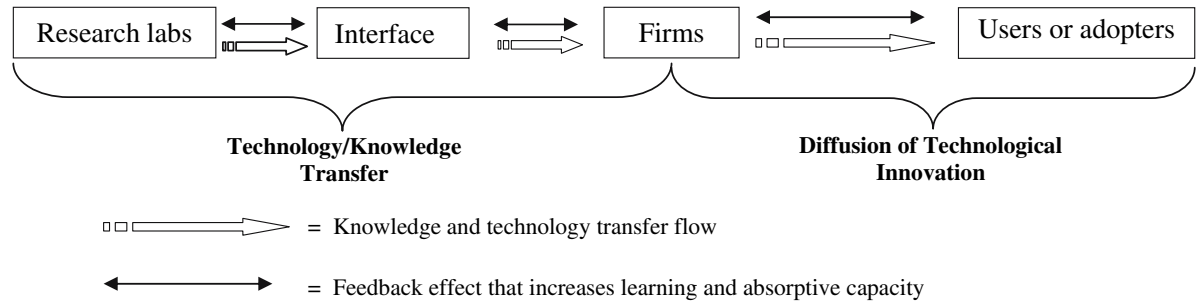

Fig. 1 Technology-knowledge transfer and diffusion process

transfer be most appropriately directed to impacts on networks of interconnected scientific and commercial subjects. Coccia $(2004,2005)$ investigates the spatial interaction of technology transfer by a series of indicators, called sensors, which consider the relationship between sources and users of technology. These indicators have provided useful information to the governance of research institutes such as the potential market which indicates the labs that are better located in proximity of the total demand and than offer greater capacity for selling the technological activities.

The localization theories of knowledge and technology not only explain that they spill over but also why they decay as they move across geographic space. Based on this theoretical framework, how can the impact of knowledge and technology transfer on geoeconomic space be measured? The following section presents a metrics to answer this important economic question.

\section{Measuring technology transfer impact: an alternative approach}

This study, using a modern approach based on evolutionary theory (Nelson \& Winter, 1982) and economics of proximity (Bellet et al., 1998; Gilly \& Torre, 2000; Boschma, 2005), analyzes the spatial mobility of technology transfer and knowledge spillover measuring their impact on domestic geo-economic system. The present research assumes the source of technology transfer as Epicenter of technology and knowledge transfer. Seismology defines epicenter the point on the Earth's surface that is directly above the point where an earthquake originates (Richter, 1958). This research, instead, considers the epicenter as the spatial point where technologies or technological competencies are originated (i.e., location of laboratories) and diffused into geo-economic area. In short, the epicenter of knowledge and technology is the point in the economic space where is located a research institute that has skilled human resources, scientific equipments, availability of capitals, and so on. Mansfield (1995, 1998) points out that research laboratory of university provide one source of innovation-generating knowledge that is available to enterprises for commercial exploitation. Jaffe (1989) supports the notion that knowledge and technology spill over for third-party from university research laboratories. Audretsch and Feldman (1996), and Feldman and Audretsch (1999) found that the knowledge created in university laboratories spills over to contribute to the generation of commercial innovations by private enterprises.

The users' knowledge and technology are small businesses, public and private institutions, and so on, that play a key role within the process of technology and knowledge transfer because they represent the recipient absorbing technological 
activities (Azzone \& Maccarone, 1997; Bozeman, 2000). Moreover, the amount of knowledge a firm is able to use economically is described by the absorptive capacity (Cohen \& Levinthal, 1990). Technology and knowledge transfer process from epicenter to users also generates knowledge spillover effects. Arrow (1962) was the first to identify externalities associated with knowledge due to its non-exclusive and non-rival use. Griliches (1992) defined knowledge spillovers as firms "working on similar things and hence benefiting much from each others research" and according to Lucas (1988, 1993) and Grossman and Helpman (1991) they are an important mechanism underlying endogenous growth.

Technology transfer carried out by public research institutes can be (Coccia \& Rolfo, 2002; Coccia, 2004, 2005): technology transfer in the strict sense such as sale or licensing of patents; construction of new product/process in collaboration with firms, and so on; technology transfer in the broad sense involves the supply of innovative services that research institute carries out thanks to the availability of scientific equipment, skilled researchers, know-how and experience in scientific and technological fields. These activities, that depend on the field where research laboratories operate, are: (a) technical analysis and testing (chemical and physical); (b) innovative know-how (i.e., specialist planning and consultation); (c) technological services (homologation, calibration, nuclear magnetic resonance, etc.); (d) quality control services (accreditation, certification, quality control, etc.); (e) environmental services (monitoring of the waters, emission control, pollution control, etc.); (f) computer-based services (data elaboration, database supply, data supply, etc.); (g) health services and activities. The users link the latter technology transfer to the ease of acquisition, comprehension and application of it. Technology transfer in the broad sense does not concern transfer of new technological prototypes, patents, but it is based on new knowledge, technical knowledge, scientific capabilities and so on, transferred into geo-economic space. This research uses the technology transfer in broad sense alike an indicator of knowledge transfer and of the latent variable knowledge spillover. Moreover, the spatial movement of technology and knowledge transfer from epicenter of knowledge to users depends on channels and mechanisms. Channel is represented by a link between two or more social bodies by which various mechanisms of technology transfer can be activated. Mechanism of technology transfer is an interaction between two or more social subjects, in which technology and knowledge are transferred (Autio \& Laamanen, 1995). These interactions can be: institutional interactions-which refer to commercial exchanges, contracts, and partnership relations-and unintentional interactions, linked for example to the presence of technological spillover (Audretsch \& Feldman, 1996). Therefore firms and research institutes have interactions and interrelatedness within a complex communication network based on interpersonal contacts (Charles \& Howells, 1992) that determine an intense flow of knowledge, technology, information and financial resources into geo-economic space. Von Hipple (1994) explains that knowledge is best transmitted via face-to-face interactions and through frequent and repeated contacts. In fact, social interactions have economic value in transmitting knowledge according to Manski (2000). A particular kind of mechanism of technology and knowledge transfer between epicenter of knowledge and users is the technological contact, generated by technological and commercial interactions. Technological contact is when the users (e.g., firms) demand to a research institute (epicenter of knowledge) a technology transfer activity in the broad sense as described before. This action generates an exchange of goods between these two subjects (knowledge or technology from research lab to user, monetary remuneration from user to research institute) in a short run (for 
instance a month and/or a year). In fact, knowledge for industrial purposes can be easily transferred and has economic value in different applications. Technological contact is a proxy of the interaction between subjects of technology-knowledge transfer process that also generates a latent knowledge spillover. Ullman (1956) argues that technological contacts (interactions) between subjects and/or economic regions depend on three factors: (a) supply-demand forces; (b) alternative supply sources of required technology; (c) cost. Typically, the highest technological contacts take place in the area where the knowledge source is located. In general, the contacts gradually decrease as the distance from the epicenter increases (except for some industrialized area, distant from the source of knowledge but highly receptive thanks to their fertile economicalindustrial structure, that generate localized effects of innovative absorption). Adams and Jaffe (2002), Adams (2002) have tried to estimate geographic extent of knowledge spillovers in miles using the concept of distance decay.

This research also considers the spatial distance that is associated with the concept of technological contact to identify the isotecne map.

Isotecne is the geometric area of all users with the same technological absorption, measured by the number of technological contacts and spatial distance from epicenter of knowledge.

Function of technology and knowledge transfer. Let $c$ be the number of contacts, and $s$ the space measured in $\mathrm{km}$ from the epicenter (epicentral distance), the function of technology an knowledge transfer is defined as $c=f(s)$ such that $c: \Re \rightarrow \Re$, continuous and differentiable function in $\Re$.

This research assumes that the price of technology transfer activities is fixed in space and short run.

Now the question is: how to measure the impact of technology and knowledge transfer of the epicenter into geo-economic space? Let me introduce the following definition.

Local magnitude of technology and knowledge transfer. Let $c=f(s)$ such that $c: \Re \rightarrow \Re$, function continuous and differentiable in $A=\{x \mid a \leq x \leq b\}$, bounded region. Let $p=$ the price of technology transferred, $c=$ the number of contacts. The local magnitude of technology and knowledge transfer is defined by

$$
\operatorname{MGT}_{\text {Local }}:=\log _{10}\left[\left(\int_{A} f(s) \mathrm{d} s\right) \cdot p \cdot c\right]=\log _{10}\left[\left(\int_{a}^{b} f(s) \mathrm{d} s\right) \cdot p \cdot c\right]
$$

Remark. If $c=f(s)$ be a bounded function on $[a, b]$, the magnitude measures the technology and knowledge transfer impact within this bounded economic space, for instance from $a=1$ to $b=200 \mathrm{~km}$.

Remark. The common logarithm of the magnitude avoids high values. Moreover, each activity of technology and knowledge transfer from epicenter to users generates a magnitude whose intensity will vary according to distance, price, cultural environment, means of communication, institutions and other factors.

Remark. If the density of technological contact is high within the bounded area, then the technological impact measured by the magnitude is high, vice versa it is low.

When considering the total spatial surface in which the technology transfer and knowledge spill over occur, the total magnitude can be defined as follows.

Total magnitude of technology and knowledge transfer. Let $i=$ the epicenter where the research institute $i$ is located. Let MGT $\left(A_{1}\right)=$ local magnitude in $A_{1}$ (e.g., 1-200 km), 
MGT $\left(A_{2}\right)=$ local magnitude in $A_{2}$; MGT $\left(A_{j}\right)=$ local magnitude in $A_{j} \ldots$ MGT $\left(A_{n}\right)=$ local magnitude in $A_{n}$. Total spatial magnitude is defined by

$$
\operatorname{MGT}_{\text {Total }}(i):=\sum_{j=1}^{n} \frac{\operatorname{MGT}_{\text {local }}\left(A_{j}\right)}{n}
$$

Remark. Total magnitude measures the impact of technology and knowledge transfer within the whole economic area where the epicenter (source of knowledge) has had technological contacts and has therefore transferred technologies and knowledge.

The technological magnitude is drawn up by means of the following steps:

- Contacts $\left(c_{i}\right)$ are aggregated in kilometric ranges. Therefore, the total number of contacts in the kilometric range $A$ between two extremes $\alpha$ and $\beta$ is the following:

$$
A=\sum_{i=\alpha}^{\beta} c_{i}
$$

where the values $\alpha, \beta$ may vary between, for instance, $1-200 \mathrm{~km}, 200-400 \mathrm{~km}$ and so on up to the last contact, in the last kilometric range. The aggregated values by area (in which the source has had contacts and technology-knowledge transfer has been spread) are therefore indicated by $A, B, C$, etc.

- $(x, y) \in R^{2}$ where $x$ is the central value of the kilometric range (e.g., 100, 300, ..) and $y$ the total number of technological contacts in the range $A, B, C$, are scattered on geometric space. The fitted line and estimation of parameters are based on the ordinary least squares (OLS) method. The function used is $y=a x^{b}$ with $a>0$, which is a continuous and differentiable function and represents $c=f(s)$, where $b=$ damping factor-measure of friction of the distance (if the value $b$ is 2 , the interaction is inversely proportional to the square of the distance).

\section{Results and findings}

Most scholars concur that states are probably too broad to represent an appropriate geographic unit of observation, and for this reason, the metrics is applied to economic regions. In particular, data are from institutes located in the Northwest of Italy, a industrialized economic region of Italy (Coccia \& Rolfo, 2002) that generate technology and knowledge with industrial use. In fact, the ability of research laboratories to create benefits for their local economies has generated a wide literature that examines the process of technology transfer from university and public research labs (Mowery \& Shane, 2002).

Moreover, this paper focuses on the domestic technology and knowledge transfer from government laboratories, in particular it analyses activities of technology transfer in the broad sense that generates knowledge transfer that is also a proxy of the latent variable knowledge spillover within geo-economic space. As described before, this kind of technology transfer is based on technological activities (calibrations, technical analysis, data elaboration, health services and so on) which are fully unfolded in a short run (e.g., a month to maximum a year) and therefore it is possible to measure it. Moreover this 
kind of technology transfer generates a high number of technological contacts, in fact the research has analyzed 1,354 invoices issued by three research institutes in the period 1997-1999. The choice fell on these documents because they are similar, homogeneous, and they have the essential elements foreseen by fiscal law. The invoices made it possible to identify the number of contacts between source and users (firms, public authorities, etc.), the geographical location of the epicenter (public research laboratories) and users, and the cost of the technological activity transferred. The results concern some institutes of the National Research Council of Italy which will be identified by their acronyms:

- IMA (Institute for Agricultural Mechanization) and IMCG (Institute of Metrology). These institutes operate within the province of Turin, with an economic structure based on automotive industry.

- IRSL (Institute for the Wool Research) is located within the province of Biella, one of the most important textile districts of Europe, where is present a high number of small firms.

The best fitted line of the scatter is a function of the following kind. $y=a x^{b}(a>0)$ that has been estimated by OLS technique. Tables 1, 2 and 3 summarize the results of the econometric analysis.

Table 1 Regression analysis (IRSL data)

\begin{tabular}{llllr}
\hline Variables & $B$ & SE $B$ & $T$ & Sig. T \\
\hline$X$ & -2.174 & 0.243 & -8.951 & 0.003 \\
Constant & $36,349,441.325$ & $53,197,849.390$ & 0.683 & 0.544 \\
\hline
\end{tabular}

$F=80.125$, sign. of $F=0.0029, R^{2}=0.964, R^{2}$ adj. $=0.952$, standard error $0.422 . X=$ independent variable $=$ spatial distance. $Y=$ dependent variable $=$ technological contacts

Table 2 Regression analysis (IMGC data)

\begin{tabular}{lrllr}
\hline Variables & \multicolumn{1}{l}{$B$} & SE $B$ & \multicolumn{1}{l}{$T$} & Sig. $T$ \\
\hline$X$ & -1.131 & 0.202 & -5.595 & 0.011 \\
Constant & $49,181.467$ & $59,911.325$ & 0.821 & 0.472 \\
\hline
\end{tabular}

$F=31.306$, sign. of $F=0.0113, R^{2}=0.913, R^{2}$ adj. $=0.883$, standard error $0.352 . X=$ independent variable $=$ spatial distance. $Y=$ dependent variable $=$ technological contacts

Table 3 Regression analysis (IMA data)

\begin{tabular}{lllll}
\hline Variables & B & SE B & T & Sig. T \\
\hline$X$ & -2.651 & 0.367 & -7.224 & 0.006 \\
Constant & $100,290,105.647$ & $221,809,424.900$ & 0.452 & 0.682 \\
\hline
\end{tabular}

$F=52.181$, sign. of $F=0.0055, R^{2}=0.946, R^{2}$ adj. $=0.928$, standard error $0.638 . X=$ independent variable $=$ spatial distance. $Y=$ dependent variable $=$ technological contacts 
After the econometric analysis, the mathematical analysis calculates the local and total magnitude (Table 4), applying the integrals on the functions:

$$
\begin{aligned}
& \text { IRSL } \quad \int 36349441.2348 x^{-2.174} \mathrm{~d} x=-30962045.34 x^{-1.174}+k \\
& \text { IMGC } \quad \int 49181.4670 x^{-1.1311} \mathrm{~d} x=-375144.6758 x^{-0.1311}+k \\
& \text { IMA } \quad \int 100290105.6465 x^{-2.6513} \mathrm{~d} x=-60734031.16 x^{-1.6513}+k
\end{aligned}
$$

The integral calculus is the basis for the calculation of magnitudes, using the formula (1) previously introduced.

$a$ and $b$ are the ranges of 1-200, 200-400 km and so on, while the price is constant (obtained by arithmetic mean of real prices of the activities transferred by institutes) and equal to $€ 200$ for IRSL, $€ 300$ for IMA and $€ 500$ for IMGC.

The degrees of empirical scale have been computed considering the difference between the max and min magnitude among the institutes into five belts $(1-200 \mathrm{~km} ; 200-400 \mathrm{~km}$; etc.).

These values are 2.5781 in $(1-200 \mathrm{~km}) ; 1.07$ in $(200-400 \mathrm{~km}) ; 1.5711$ in $(400-600 \mathrm{~km})$; 2.6068 in $(600-800 \mathrm{~km}) ; 2.6274$ in $(800-1,000 \mathrm{~km})$. The arithmetic mean of these values is 2.09. We start from max magnitude (12.9708), which is the lower value of VI degree that represents the higher intensity, and we reduce it by 2.09 to have the lower value (10.88) of $\mathrm{V}$ degree, after that $10.88-2.09=8.79$ is the lower value of IV degree; $8.79-2.09=6.69$ is the lower value of III degree; and in all 6.69-2.09=4.61 is the lower limit of II degree; the I degree of intensity considers magnitude lower of 4.61 .

Using the local magnitude in the range 1-200, the last column in Table 5 shows that IMGC has an high impact of technology and knowledge transfer on the domestic geoeconomic environment (IV degree), IMA very high (V degree) and IRSL extremely high (VI degree). If we consider other kilometric range, it is possible to find the intensity of

\begin{tabular}{|c|c|c|c|c|c|c|}
\hline \multirow[t]{2}{*}{ Km belts (range) } & \multicolumn{2}{|c|}{$\operatorname{IRSL}(p=200 €)$} & \multicolumn{2}{|c|}{$\operatorname{IMGC}(p=500 €)$} & \multicolumn{2}{|c|}{ IMA $(p=300 €)$} \\
\hline & $\begin{array}{l}\text { No. } \\
\text { contacts }\end{array}$ & $\begin{array}{l}\text { Local } \\
\text { magnitude }\end{array}$ & $\begin{array}{l}\text { No. } \\
\text { contacts }\end{array}$ & $\begin{array}{l}\text { Local } \\
\text { magnitude }\end{array}$ & $\begin{array}{l}\text { No. } \\
\text { contacts }\end{array}$ & $\begin{array}{l}\text { Local } \\
\text { magnitude }\end{array}$ \\
\hline $1-200$ & 1,513 & 12.9708 & 263 & 10.3927 & 317 & 12.7615 \\
\hline $200-400$ & 216 & 9.1706 & 83 & 8.8294 & 64 & 8.1006 \\
\hline $400-600$ & 40 & 7.9175 & 34 & 8.1776 & 9 & 6.6065 \\
\hline $600-800$ & 15 & 7.1637 & 48 & 8.1585 & 2 & 5.5517 \\
\hline $800-1,000$ & 20 & 7.0473 & 17 & 7.5829 & 1 & 4.9555 \\
\hline $1-1,000$ & 1,804 & 13.0480 & 445 & 10.6966 & 393 & 12.8549 \\
\hline Total magnitude & & 8.854 & & 8.628 & & 7.595 \\
\hline
\end{tabular}
technological impact of several labs.

Table 4 Local and total magnitude of the technological transfer from the epicenters 

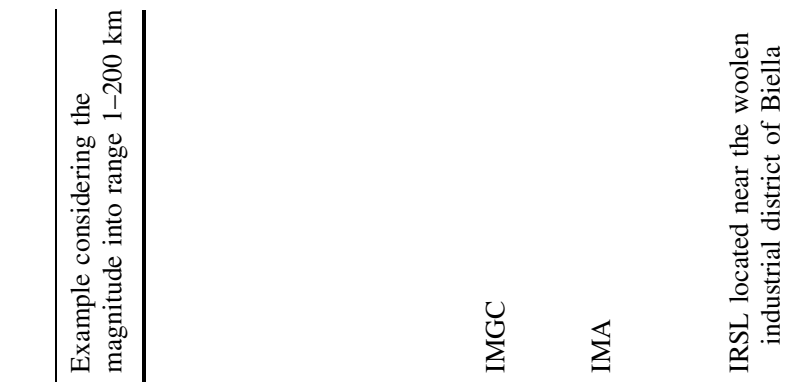

咅

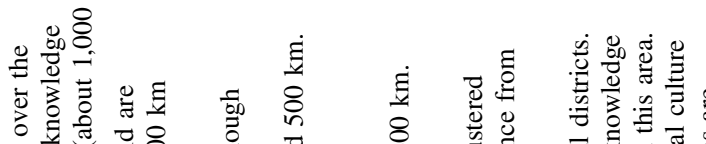

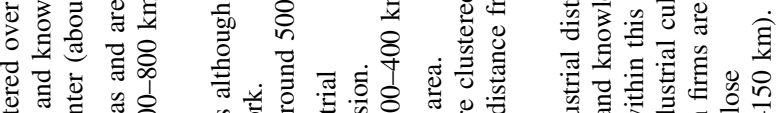

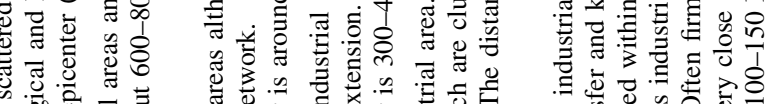

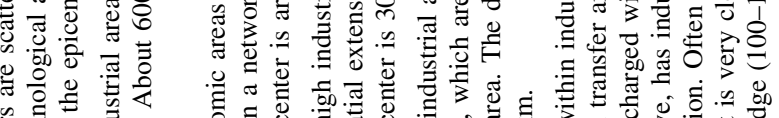

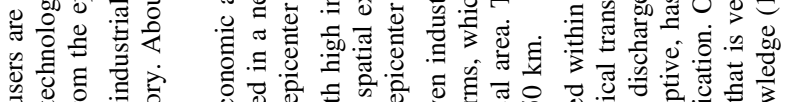

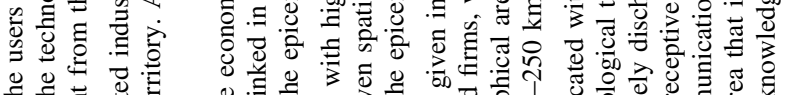

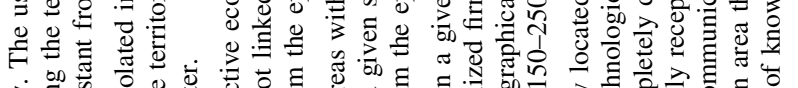

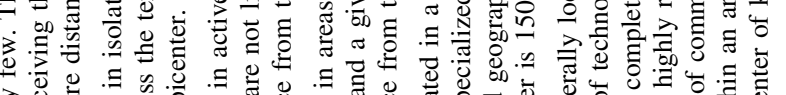

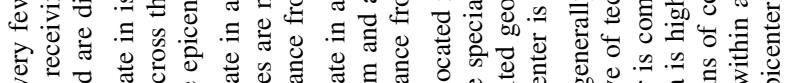

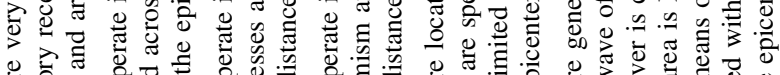

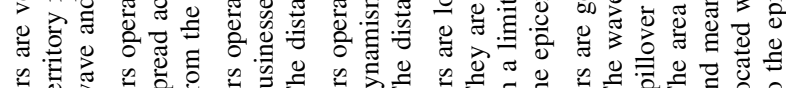

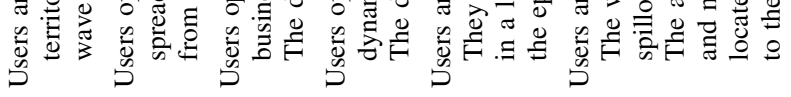


Fig. 2 Isotecne of technology and knowledge transfer impact in the real domestic geo-economic space: the case of the IRSL Institute. (-) Isotecne is the geometric place of all adopters with the same intensity of technological and knowledge spillover absorption, measured by the number of contacts

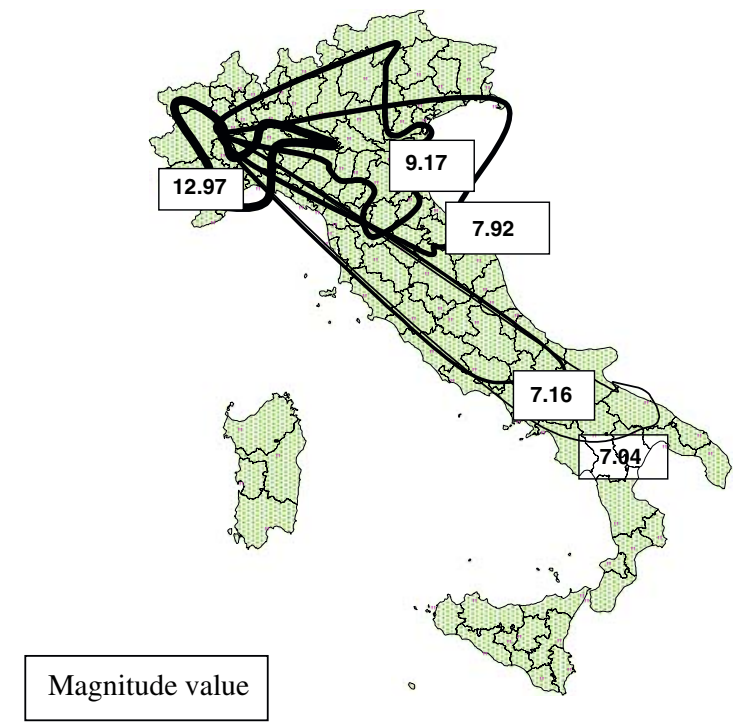

This empirical scale presents a classification by degrees (I to VI) of economic impact of technology and knowledge transfer according to the density of technological interactions within fixed kilometric ranges between the knowledge epicenter - and users. Figure 2 shows, in the case of IRSL institute, the isotecne map, uniting the points that have the same number of technological contacts, that indicates different impact areas of technological and knowledge transfer (isotecne) within Italian geo-economic space. Figure 2 also shows that knowledge transfer impact around the epicenter (i.e., research lab) has not symmetric circles (areas) but amorphous shapes, distorted by distance and other factors. Moreover, empirical evidence has shown that small variations in the magnitude, for example 0.20 0.50 points, must not be seen as minor variations in the effects and/or absorptive capacity of geo-economic environment. It must be noted that the construction of the magnitude is in logarithmic scale and therefore small variations in its value are translated into major effects on the receiving domestic geo-economic environment. For instance, if the magnitude increases of 0.50 , the number of adopters can increase by thousands of units.

The analysis shows that the spatial mobility of technology and knowledge from epicenter generates two main areas of impact:

- Small intensive area where there is a very high impact of knowledge and technology transferred on geo-economic space. The border of this area is within $200 \mathrm{~km}$ from the epicenter (e.g., the area has high impact: 12.97 in Fig. 2).

- Large areas involve a spatially larger domestic geo-economic areas, with lower impact of technological and knowledge transfer from epicenter to geo-economic systems.

\section{Discussion and concluding remarks}

The literature on geography of innovation has begun to consider the mechanism by which knowledge (technology) spills over and is put into economic use, and the degree to which these processes are geographically localized. Understanding these issues are important because a policy implication commonly drawn from new economic growth theory is that, 


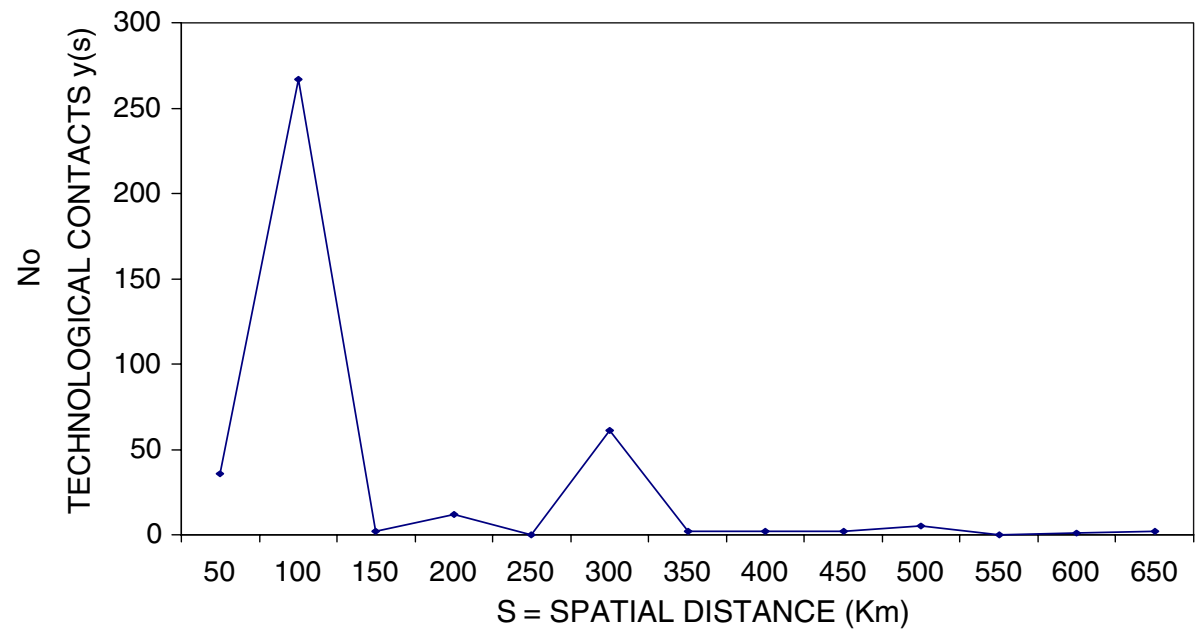

Fig. 3 Spatial pulsations of technological and knowledge transfer of IMA

due to convexities in knowledge and the resultant increasing return, knowledge resources should be supported by incentives to increase their production, diffusion and absorption. It is important to recognize that the paths that knowledge and technology take and their impact on geo-economic space play a key role and may serve as a focus for public policy enhancing economic growth and development. Figures 3 and 4 show that although IMA and IRSL Institutes are located in different economic regions and transfer different technologies, the spatial path of technology transfer (that has also a component of knowledge spillover) always displays dampened pulsations over space, as they move away from the epicenter (location of research institute).

In particular, the main pulsations of IRSL and IMA fall at $100 \mathrm{~km}$, at about $300 \mathrm{~km}$, $387 \mathrm{~km}$ for IRSL (500 km for IMA), and $675 \mathrm{~km}$ (only IRSL), decreasing in impact (width) as they become more distant from the epicenter (location of institutes).

Figures show that a high impact of technology and knowledge is within the area of 200 $\mathrm{km}$ from research laboratories and this confirms that technological transfer and knowledge spillovers of institutes are spatially bounded. Krugman (1991) confirms that knowledge

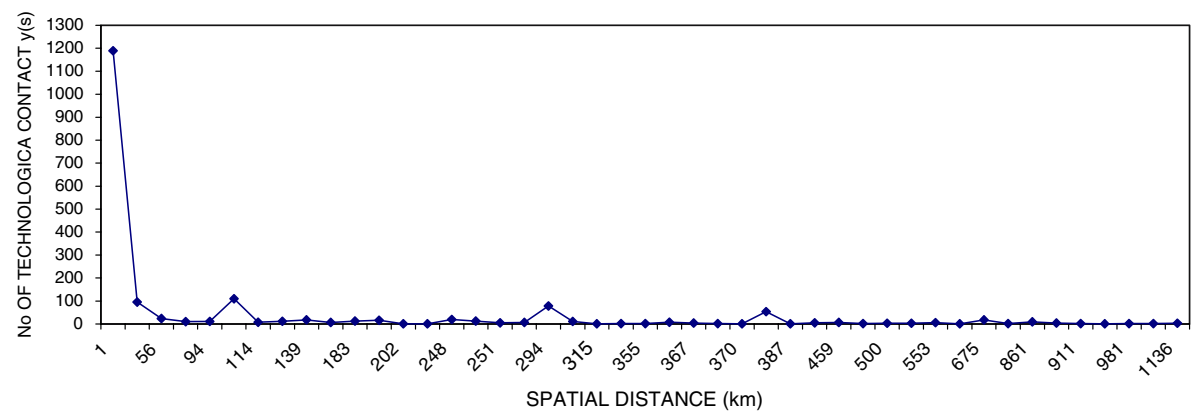

Fig. 4 Spatial pulsations of technological and knowledge transfer of IRSL 
externalities are important and forceful but are spatially bounded. Agrawal (2002) and others also concur that knowledge spillovers tend to be geographically bounded within the region where new economic knowledge was created. Although the knowledge and technology are spatially bounded, this research shows that users has on geo-economic space different intensity of absorption. In fact, knowledge and technology impact is not homogeneous within economic space but heterogeneous and generate different impact areas according to economic structure of receiving system. The IRSL institute has a high impact of knowledge transfer within the textile industry where resources have been accumulated due to industrial district past success (Feldman, 1994). Autant-Bernard (2001) and Orlando (2000) suggest the importance of geographic proximity for spillover is dependent on the propensity of similar industrial activity to agglomerate geographically. In fact, absorptive capacity of users is higher where there is geographic concentration of production, research, and skilled labor that are important inputs. In short, empirical evidence suggests the location and geographic proximity matter in exploiting technology transfer and knowledge spillover.

Why knowledge and technology transfer have different impact on geo-economic space?

Scholars have long argued that differences in the culture of a region and relationship between actors may contribute to difference in innovative performance across economic areas (Malecki, 1997). Rosenthal and Strange (2003) state that the underlying economic structure within geographic unit might shape absorption of knowledge. Glaeser, Kallal, Scheinkman, and Sheifer (1992) suggest that an increased concentration of a particular industry within a specific region facilitates knowledge spillover and technology transfer across firms. Furthermore, the different impacts of localized knowledge and technology transfer on geo-economic areas are closely linked to the absorptive capacity: the ability of economic agents to recognize, assimilate and apply new scientific knowledge and technology for its innovation and new product development (Agrawal, 2002). Cohen and Levinthal $(1989,1990)$ argue that a firm's ability to utilize knowledge and technology for its own commercial gain is a function of its investment in R\&D. Cockburn and Henderson (1998) add that the degree to which firms are connected is also important for utilizing technology and knowledge spillover. Lim (2004) adds that the absorptive capacity is primarily a function of its connectedness, of which its investments in R\&D is just one of several elements that also include cultivating university and public research labs relationships, recruiting graduate students, participating in research consortia, partnering with other companies that do related scientific research. This explains the high intensity degree of technology transfer impact and absorptive capacity of small firms operating in the industrial district of Biella. In fact, these small businesses are able to acquire externally generated scientific knowledge without conducting in-house research, but by interactions with public research bodies. Therefore the concepts of technology transfer, knowledge spillover and absorptive capacity are closely related (Agrawal, 2002).

What are the elements that affect the spatial mobility of technology and knowledge?

They depend on: (a) the force of attrition generated by the space, which more than doubles as the distance from the epicenter increases (see the exponent of the function of technology and knowledge transfer that is: $-2.17 ;-1.13 ;-2.65$ ); (b) the location of rich industrial areas; (c) learning effects and absorptive capacity. The direction of technology and knowledge transfer flow is shown in Fig. 5 (in the case of IRSL) by linking, within the isotecne, the points of maximum impact. The direction of spatial mobility of technology and knowledge is related to the concentration of adopters in some main industrial areas (such as the Italian textile districts in this specific case study) along the Italian geoeconomic space. 
Fig. 5 Direction of technological and knowledge transfer from the IRSL Institute

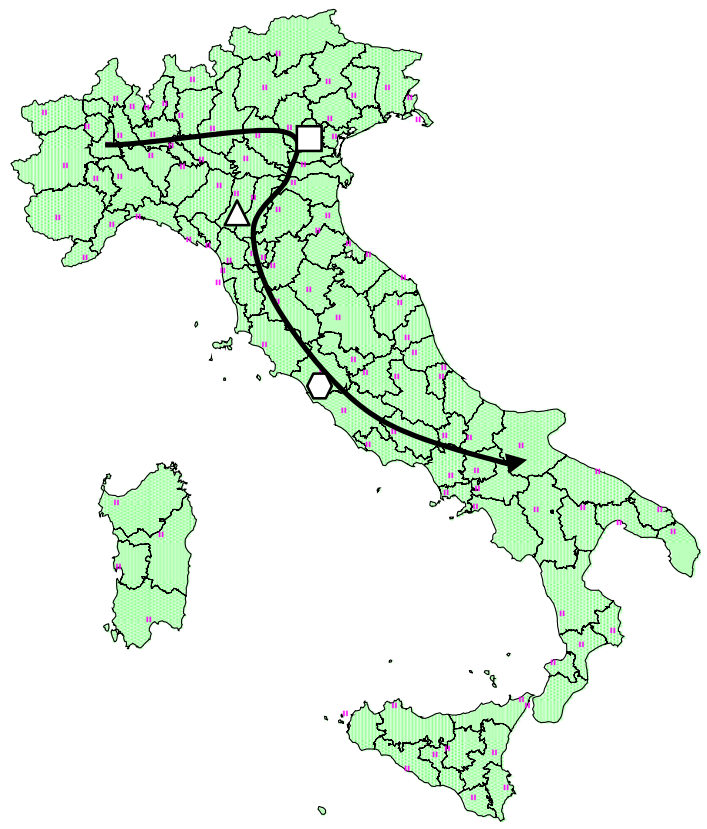

The lessons learned can be synthesized in the following points:

- Although we have analyzed different research institutes, located in different economic areas, the economic impact of knowledge transfer is similar: when the distance from the source of knowledge increases, the absorption of technology and knowledge decreases with damped pulsations over space (see Figs. 3 and 4). In particular, the knowledge and technology transfer impact can be represented by this function $f(t)$ :

$$
f(t)=\mathrm{e}^{h t}(\alpha \cos 2 \pi \omega t+\beta \sin \cos 2 \pi \omega t) \quad \operatorname{con} h<0 .
$$

- Technology transfer and knowledge spillover's users of the institutes analyzed are small firms. In fact, Acs et al. (1994) state that research made by public universities and labs serve as a key input for generating innovative activity in small enterprises. Large firms are more adept at exploiting knowledge created in their own laboratories, while smaller counterparts have a competitive advantage at exploiting spillover from university laboratories.

- The isotecne map (Fig. 2) shows a high economic impact of knowledge spillover and technology transfer within industrial districts where the density of technological contacts between institutes and firms is high. The effect of this high impact can derive from a process of coincidence/articulation between geographical, organizational and institutional proximity. The analysis of the IRSL case is important because it shows how the territorial anchorage of the process of technology and knowledge transfer is largely conditioned by what Amin and Thrift (1995) called institutional thickness. Institutional thickness refers both to the interactions that various players are capable of creating amongst themselves and to the collective representation and participation in a common project. Within industrial districts, the collective rules act as collective 
knowledge devices that make collective learning possible. Moreover, high level of knowledge absorption in industrial districts is also due to skilled labor as mechanism for knowledge transfer (Malecki, 1997).

- The spatial mobility of technology and knowledge depends on a series of factors:

- Intrinsic to technology and knowledge transferred. Sahal (1981) states that during its process of diffusion, technological innovation undergoes changes according to its functional and structural properties;

- Environmental, linked to the economic conditions where the technological knowledge is originated and diffused (distance of users from epicenter, type and content of industrial reality, availability of financial resources, accumulation of knowledge, learning effects, etc.);

- Social, depending on whether the cultural level of the population affects technological receptivity.

- Different levels of absorption within the domestic geo-economic space depend on different levels of learning by doing, by using, by interacting and absorptive capacity.

- High technological magnitude and low spatial friction, measured by this metrics, indicate research labs that are better located and therefore offer greater chances of diffusing knowledge and transfer technological activities within geo-economic space.

In fact, to find different technology and knowledge transfer impacts can be useful to describe the absorptive capacity of firms to predict their action and to suggest a framework of research and technology policy. In this case policy-makers may strength some industrial areas, reducing spatial friction by interfaces (technology transfer offices, liaison offices, etc.) to increase the level of absorption of knowledge, more and more useful to competitiveness of firms and regional economic development. This alternative approach provides crucial information to define a map of areas of different impact of knowledge transfer, different levels of absorption, size of the knowledge market transferred by research labs, attraction of technological activities, etc. For instance, the technological magnitude is high in wool research labs (IRSL) located in an industrial district (near Switzerland) with a high concentration of textile small firms. This shows that IRSL is better located than IMA and IMGC in relation to the demand of technology produced.

The results may be generalized for technology transfer's activity carried out by research laboratories located in industrialized regions. In fact, Italian research institutes analyzed operate in economic regions that are similar to those of other European countries. Therefore, the findings can provide useful information to policy makers, who nowadays have to support powerful innovation policies in several European areas that often have similar structures, industries and socio-economic problems (e.g., low competitiveness and employment). Policy makers, within the national or regional system of innovation (Lundvall, 1992; Braczyk, Cooke, \& Heidenreich, 1998), could locate the research institute where there is a high demand for technology, measured by the magnitude. In fact, where the demand is high, there are greater opportunities to transfer and spread technology knowledge into geo-economic space, to increase the competitiveness of firms and the interactions of triple helix mechanism with benefits for regional economic growth.

The empirical scale of spatial impact of technology and knowledge, even if it depends on institutes analyzed, is a starting point to measure and classify the economic impact on geo-economic space by an alternative approach. The function of one real variable used to calculate the technological magnitude is a simplification, because there are many variables that could affect the spatial mobility and impact of technology and knowledge. This alternative technometric approach uses the physical distance to measure the geographical 
proximity but Feldman (2002) and Branstetter (2004) argues that the measures of distance do not capture complex social relationships. Moreover even if the mechanism of transmitting knowledge remains unknown, this paper considers as proxy the technological contact. The future development of the research will be based on functions of several real variables to increase the accuracy of the measurement of technology knowledge transfer impact and the standardization of intensity degrees, to have a uniform metrics of the impact of technology and knowledge, for all research labs, over time and geo-economic space. The path will be arduous and long, since the mobility of technology transfer and knowledge spillover is a complex variable and the analysis and measurement cannot be related to a single topic, but difficulties often are challenges to be taken up.

Acknowledgements I am very grateful to Prof. Secondo Rolfo (Ceris-CNR, Italy) for his valuable advice and constant support, Alfred Kleinknecht, Technische Universiteit (Delft, The Netherlands) and Simona Iammarino SPRU (UK) for useful suggestions. I have also benefited from the comments of conference participants at 4th European Meeting on Applied Evolutionary Economics (EMAEE), Urban and Regional Research Centre, Utrecht, The Netherlands, and two anonymous referees. Particular thanks go to Mr. Diego Margon and Mrs. Silvana Zelli for the research assistance. Any remaining errors or omissions to be found in the text are my sole responsibility.

\section{References}

Acs, Z. J., Audretsch, D. B., \& Feldman, M. R. (1994). R\&D spillovers and recipient firm size. Review of Economics and Statistics, 76(2), 336-340.

Adams, J. D., \& Jaffe, A. B. (2002). Bounding the effects of R\&D: An investigation using matched firm and establishment data. Rand Journal of Economic, 27(4), 700-721.

Adams, J. D. (2002). Comparative localization of academic and industrial spillovers. Journal of Economic Geography, 2(3), 253-278.

Aghion, P., \& Howitt, P. (1998). Endogenous growth theory. The MIT Press.

Agrawal, A. (2002). Innovation, growth theory and the role of knowledge spillovers. Innovation Analysis Bulletin, 4(3), 3-6.

Amin, A., \& Thrift, N. (1995). Globalisation, institutional thickness and local prospects. In P. Healey (Ed.), Managing cities. Wiley.

Antonelli, C. (1995). The economics of localized technological change and industrial dynamics. Norwell, MA: Kluwer Academic Publishers.

Arrow, K. (1962). Economic welfare and the allocation of resources for invention. In Nelson R. R. (Ed.), The rate and direction of inventive activity: Economic and social factors, Princeton: Princeton University Press.

Asheim, B., \& Gertler, M. (2005). The geography of innovation: Regional innovation systems. In J. Fagerberg, D. C. Mowery, \& R. R. Nelson (Eds.), The Oxford handbook of innovation (Ch. 11, pp. 291317). Oxford: Oxford University Press.

Audretsch, D. B., \& Feldman, M. P. (1996). R\&D spillovers and the geography of innovation and production. American Economic Review, 86(3), 630-640.

Autant-Bernard, C. (2001). The geography of knowledge spillovers and technological proximity. Economics of Innovation and New Technology, 10(4), 237-254.

Autio, E., \& Laamanen, T. (1995). Measurement and evaluation of technology transfer: Review of technology transfer mechanisms and indicators. International Journal of Technology Management, 10(78), 643-664.

Azzone, G., \& Maccarone, P. (1997). The emerging role of lean infrastructures in technology transfer: The case of the innovation plaza project. Technovation, 17(7), 391-402.

Bellet, M., Kirat, T., \& Largeron, C. (1998). Approches multiformes de la proximité. Paris: Hermès.

Boschma, R. A. (2005). Proximity and innovation: A critical assessment. Regional Studies, 39(1), 61-74.

Bozeman, B. (2000). Technology transfer and public policy: A review of research and theory. Research Policy, 29(4-5), 627-655.

Braczyk, H., Cooke, P., \& Heidenreich, M. (1998). Regional innovation systems. London: UCL Press.

Branstetter, L. (2004). Exploring the link between academic science and industrial innovation. Discussion paper No. 29 APEC Study Center Columbia Business School. 
Brown, L. (1968). Diffusion dynamics: A review and revision of the quantitative theory of the spatial mobility of innovation. Lund Studies in Geography, Series B, XXIX.

Charles, D., \& Howells, J. (1992). Technology transfer in Europe. London: Belhaven Press.

Coccia, M., \& Rolfo, S. (2002). Technology transfer analysis in the Italian National Research Council. Technovation, 22(5), 291-299.

Coccia, M. (2004). Spatial metrics of the technological transfer: Analysis and strategic management. Technology Analysis \& Strategic Management, 16(1), 31-51.

Coccia, M. (2005). Metrics to measure the technology transfer absorption: Analysis of the relationship between institutes and adopters in northern Italy. International Journal of Technology Transfer and Commercialization, 4(4), 462-486.

Coccia, M. (2006). Analysis and classification of public research institutes. World Review of Science, Technology and Sustainable Development, 3(19), 1-16.

Cockburn, I., \& Henderson, R. (1998). Absorptive capacity, co-authoring behaviour, and the organization of research in drug discovery. The Journal of Industrial Economics, 46(2), 157-182.

Cohen, W. M., \& Levinthal, D. A. (1989). Innovation and learning: The two faces of R\&D. The Economic Journal, 99(3), 569-596.

Cohen, W. M., \& Levinthal, D. A. (1990). Absorptive capacity: A new perspective on learning and innovation. Administrative Science Quarterly, 35(1), 128-152.

Daft, R. L., \& Lengel, R. H. (1986). Organizational information requirements, media richness and structural design. Management Science, 32(1), 554-571.

David, P. A. (1993). Path-dependence and predictability in dynamic systems with local network externalities: A paradigm for historic economics. In D. Foray \& C. Freeman (Eds.), Technology and the wealth of nations, London: Pinter.

Etzkowitz, H., \& Leydesdorff, L. (2000). The dynamics of innovation: From national systems and "mode 2', to a triple helix of university-industry-government relations. Research Policy, 29(2), 109-123.

Feldman, M. P., \& Audretsch, D. (1999). Innovation in cities: Science-based diversity, specialization and localized competition. European Economic Review, 43(2), 409-429.

Feldman, M. P. (1994). The geography of innovation. Boston: Kluwer Academic.

Feldman, M. P. (2002). The internet revolution and the geography of innovation. International Social Science Journal, 54(171), 47-56.

Gilly, J. P., \& Torre, A. (2000). Dynamiques de Proximité. Paris: L'Harmattan.

Glaeser, E., Kallal, H., Scheinkman, J., \& Sheifer, A. (1992). Growth of cites. Journal of Political Economy, $100(6), 1126-1152$.

Griliches, Z. (1992). The search for R\&D spillovers. Scandinavian Journal of Economics, 94(Suppl), $29-47$.

Grossman, G. M., \& Helpman, E. (1991). Innovation and growth in the global economy. Cambridge, MA: MIT Press.

Hägerstrand, T. (1967). Innovation diffusion as a spatial process. Chicago: The University of Chicago Press.

Jaffe, A. B. (1989). Real effects of academic research. American Economic Review, 79(5), 957-970.

Keilbach, M. C. (2000). Spatial knowledge spillovers and the dynamics of agglomeration and regional growth, contributions to economics. Heidelberg: Physica-Verlag.

Kremic, T. (2003). Technology transfer: A contextual approach. The Journal of Technology Transfer, 28(2), $149-158$.

Krugman, P. (1991). Geography of trade. Cambridge: MIT Press.

Lim, K. (2004). The many faces of absorptive capacity: Spillovers of copper interconnect technology for semiconductor chips. Working paper series, Available at SSRN, Melbourne Business School.

Lucas, R. E. (1988). On the mechanics of economic development. Journal of Monetary Economics, 22(1), $3-42$.

Lucas, R. E. (1993). Making a miracle. Econometrica, 61(2), 251-272.

Lundvall, B. A., \& Johnson, B. (1994). The learning economy. Journal of Industry Studies, 1(2), $23-42$.

Lundvall, B. A. (1992). National systems of innovation. London: Pinter Publishers.

Malecki, E. J. (1997). Technology and economic development. Essex, UK: Addison Wesley Longman.

Malerba, F. (1992). Learning by firms and incremental technical change. Economic Journal, 102(413), 845859.

Mansfield, E., (1995). Academic research underlying industrial innovations: Sources, characteristics, and financing. Review of Economic and Statistics, 77(1), 55-65.

Mansfield, E. (1998). Academic research and industrial innovations: An update of empirical finding. Research Policy, 26(7-8), 773-776.

Manski, C. F. (2000). Economic analysis of social interactions. Journal of Economic Perspectives, 14(3), $115-136$. 
Meagher, K., \& Roger, M. (2004). Network density and R\&D spillover. Journal of Economic Behaviour and Organization, 53(2), 237-260.

Mowery, D. C., \& Shane, S. (2002). Introduction to the special issue on university entrepreneurship and technology transfer. Management Science, 48(1), 1-6.

Nelson, R., \& Winter, S. (1982). An evolution theory of economic change. Cambridge: Belknap Press of Harvard University.

Orlando, M. J. (2000). On the importance of geographic and technological proximity for R\&D spillovers: An empirical investigation. Federal Reserve Bank of Kansas City Research Working Paper.

Pecqueur, B., \& Zimmermann, J.B. (2004). Economie de Proximités. Paris: Hermès.

Perroux, P. (1967). L'economia del XX secolo. Milano: Etas.

Polanyi, M. (1966). The tacit dimension. Garden City, NY: Doubleday.

Porter, M. (1990). The competitive advantage of nations. London: The Macmillan.

Premus, R. (2002). Moving technology from labs to market: A policy perspective. International Journal of Technology Transfer and Commercialization, 1(1-2), 22-39.

Rappa, M. A., \& Debackere, K. (1992). Technological communities and the diffusion of knowledge. $R \& D$ Management, 22(3), 209-220.

Richter, C. F. (1958). Elementary seismology. San Francisco: Freeman.

Roessner, J. D., \& Bean, A. (1994). Patterns of industry interaction with federal laboratories. The Journal of Technology Transfer, 19(3/4), 59-77.

Rogers, E. M., Takegami, S., \& Yin, J. (2001). Lessons leaned about technology transfer. Technovation, 21(4), 253-261.

Romer, P. M. (1990). Endogenous technological change. Journal of Political Economy, 98(5), 71-102.

Rosenberg, N. (1982). Inside the black box. Cambridge: Cambridge University Press.

Rosenthal, S. S., \& Strange, W. C. (2003). Geography, industrial organization, and agglomeration. Review of Economics and Statistics, 85(2), 377-393.

Sahal, D. (1981). Patterns of technological innovation. Massachusetts: Addison-Wesley.

Saxenian, A. (1995). Regional advantage: Culture and competition in Sylicon valley and route 128. Cambridge: Harvard University Press.

Singh, J. (2005). Collaborative networks as determinants of knowledge diffusion patterns. Management Science, 51(5), 756-770.

Sutton, J. (1998). Technology and market structure: Theory and history. Cambridge: MIT Press.

Torre, A., \& Mollard, A. (2004). Proximity and environmental dimensions. International Journal of Sustainable Development, 7(3), 221-236(special issue).

Torre, A., \& Rallet, A. (2005). Proximity and localization. Regional Studies, 39(1), 47-60.

Ullman, E. L. (1956). The role of transportation and the bases for interaction. In W. Thomas (Ed.), Man's role in changing the face of the earth. Chicago: Chicago University Press.

Von Hipple, E. (1994). Sticky information and the locus of problem solving: Implications for innovation. Management Science, 40(4), 429-439.

Wersching, K. (2005). Innovation and knowledge spillover with geographical and technological distance in an agent based simulation model. Discussion Paper, no. 535, Bielefeld University, Germany.

Zucker, L. G., Darby, M. R., \& Armstrong, J. (1998). Geographically localized knowledge: Spillovers or markets? Economic Inquiry, 36(1), 65-86. 